\title{
SIMULANDO IMPACTOS REGIONAIS DE CHOQUES DE PRODUTIVIDADE: O CASO DA REGIÃO NORDESTE
}

\author{
Carlos Wagner de Albuquerque Oliveira ${ }^{2}$ \\ Bruno de Oliveira $\mathrm{Cruz}^{3}$
}

\section{INTRODUÇÃO}

Entre os principais desafios da economia brasileira, encontra-se a melhoria de sua produtividade como um todo. Após anos de desenvolvimento modesto, diversas linhas de pensamento têm defendido o avanço da produtividade como uma das principais prescriçóes de política para a retomada do crescimento. $\mathrm{O}$ Brasil, contudo, além de suas desigualdades financeiras interpessoais, convive com uma forte discrepância de renda em termos regionais. Assim, a questáo que se coloca aqui é: qual seria o impacto nas regióes brasileiras de uma política nacional de melhoria de produtividade, sem qualquer foco regional? Em outras palavras, apenas uma política nacional de melhoria de produtividade e crescimento seria suficiente para reduzir as desigualdades? Mais além, o impacto seria tanto no crescimento do produto interno bruto (PIB) per capita regional como na reduçáo da pobreza?

Este artigo aborda essas questôes comparando um cenário tendencial com políticas alternativas de crescimento da produtividade. Utilizando-se um modelo desenvolvido pela Universidade de Denver, que constrói cenários para a economia mundial, com vários blocos e interação de diversas variáveis, as simulaçôes mostram que, mesmo em um cenário otimista de recuperação do crescimento e a economia do Nordeste se desenvolvendo acima da média nacional, o nível do PIB per capita da região não atingiria 60\% do PIB per capita nacional em 2030. Os resultados apontam a necessidade de pensar intervençôes focadas no território para que o crescimento possa impulsionar ainda mais as regiôes menos desenvolvidas do país.

Estruturamos este artigo delineando dois possíveis cenários acerca do comportamento do PIB per capita dos estados que compóem a região Nordeste do Brasil. Esses cenários serấo comparados entre si e com a projeçáo do comportamento do PIB per capita do Brasil como um todo, de outros países e grupos de países. Ainda será apresentada uma pequena digressão sobre o comportamento da pobreza no Brasil e no Nordeste, a partir do conceito

1. DOI: http://dx.doi.org/10.38116/brua22art3

2. Técnico de planejamento e pesquisa na Diretoria de Estudos e Políticas Regionais, Urbanas e Ambientais (Dirur) do Ipea. E-mail:<carlos.wagner@ipea.gov.br>.

3. Técnico de planejamento e pesquisa na Dirur/lpea. E-mail: <bruno.cruz@ipea.gov.br>. 
de linha de pobreza medida pelo critério de US $\$ 1.25$ recebido pelo cidadão para fazer face às suas despesas diárias. Também, de forma bastante simplificada, a estrutura do modelo computacional subjacente às projeçôes feitas aqui será apresentada. Por fim, algumas recomendaçóes finalizarão o artigo.

\section{MODELO COMPUTACIONAL}

International Futures (IFs) é um sistema integrado, desenvolvido por Frederick S. Pardee Center for International Futures, da Universidade de Denver, e foi idealizado para gerar estimativas de impacto de longo prazo. Com uma base de dados cuja cobertura atinge cerca de 186 países, o sistema IFs cria possibilidades de análises interativas entre seus subsistemas, denominados: agricultura, demografia, economia, educação, energia, meio ambiente, saúde, infraestrutura e sociopolítica.

O IFs é resultado de um projeto iniciado em 1980 e hoje se encontra em sua sétima geração. Ao longo desses anos, o projeto foi incorporando avanços tanto no uso de linguagem de programação quanto em modelagem e base de dados. Contudo, seus idealizadores não o consideram um projeto finalizado, mas como "uma ferramenta viva que está constantemente evoluindo". Trata-se de um sistema livre e disponível para download ou para ser usado na forma off-line; tem código aberto e, portanto, é passível de receber contribuiçóes externas de seus usuários; sua forma integrada e ampla permite entender a multiplicidade dos impactos globais e como cada sistema age sobre o outro; e pode ser usado para previsóes em nível global, nacional ou regional.

O sistema IFs toma por base, para suas estimativas, os dados históricos até 2015, cujas previsôes podem se estender para valores até 2100. As análises históricas e as "previsôes" também incluem uma extensa e crescente base de dados históricos, iniciada em 1960. O uso da ferramenta IFs permite exibir resultados em nível de país, região ou grupos menores que podem ser as Unidades da Federação (UFs) no Brasil. A figura 1 exemplifica de forma esquemática as relaçôes estabelecidas pelo modelo.

FIGURA 1

Representação visual de IFs

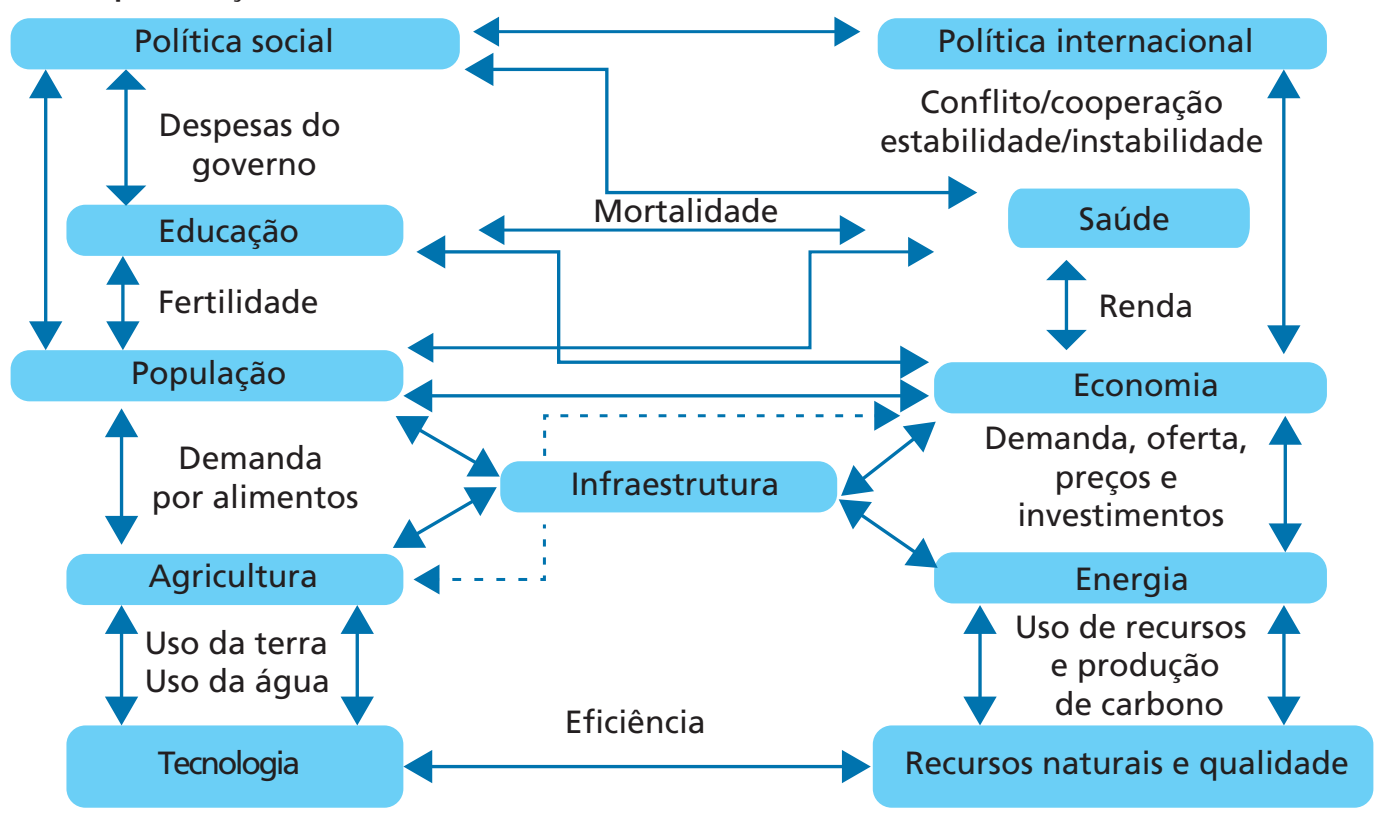

Fonte: IFs - Training Manual, 2015. 
Sempre que o programa do sistema é iniciado, o cenário base (base case) por default é apresentado. Esse cenário não se refere à estimativa de tendência, mas sim à dinâmica do modelo na ausência de qualquer intervenção. Em outras palavras, o cenário base mostra o comportamento das variáveis inseridas no modelo conforme as equações que descrevem as açôes dos agentes. Ainda é possível modificar os parâmetros das equaçôes e as condiçóes iniciais do modelo. Essa flexibilidade permite ao usuário simular um conjunto de intervençóes ou mudanças tecnológicas e estimar o impacto dessas mudanças nas variáveis do modelo. Além da possibilidade dada pela ferramenta de medir impactos de políticas públicas, ela permite, com a construçáo de cenários, apresentar pontos de vista alternativos àqueles que se encontram na corrente principal do pensamento vigente. A ferramenta também comporta o uso de cenários pré-configurados, construídos por terceiros.

O modelo contempla diversos módulos: economia e finanças, com um bloco macroeconômico; blocos sociais modelando educação, demografia e saúde; e módulos incluindo infraestrutura, meio ambiente e energia. Além disso, há uma modelagem de aspectos qualitativos do governo, política internacional e tecnologia. A vantagem dessa ferramenta está na possibilidade de incluir no modelo bases de dados de diversos países, além de possuir séries estatísticas cobrindo todos esses tópicos. Assim, os efeitos estimados incluem o transbordamento e a interação entre os países e cenários para diversas variáveis. ${ }^{4}$

Os módulos dos sistemas estão integrados, por meio de uma estrutura híbrida (modelos de equilíbrio geral e modelos econométricos), de forma que um choque exógeno em uma variável ou mais variáveis em um dos módulos afeta o equilíbrio dos demais. Não cabe aqui uma descrição algébrica do modelo, uma vez que essa tarefa não faz parte do propósito deste artigo. É possível, no entanto, acessar detalhes do funcionamento e as relaçôes funcionais de todo o sistema IFs por meio da página da internet de Frederick S. Pardee Center for International Futures. ${ }^{5}$

Somente com o intuito de ilustrar o comportamento do modelo, vamos tomar como exemplo o módulo denominado economia. Nesse módulo, o IFs roda um modelo de equilíbrio geral computável que comporta, para cada regiáo ou país, uma matriz de contabilidade social agregada em seis setores (agricultura, energia, indústrias extrativas, indústria de transformação, serviços e o setor de comunicação e tecnologia). As famílias também estão desagregadas em dois tipos: qualificado e não qualificado. A forma funcional da função de produção é do tipo Cobb-Douglas tradicional, cujos fatores de produção são capital e trabalho e a constante produtividade total dos fatores, determinados endogenamente. A produçáo de bens e serviços é considerada o núcleo dinâmico dessa estrutura, visto que é determinante no cálculo da taxa de crescimento e no tamanho da economia no longo prazo.

Assim, a função de produção é descrita, de forma genérica, como:

$$
Y=A K^{\alpha} L^{\beta}
$$

Em que $Y$ é o produto; $A$ representa a produtividade total dos fatores; $K$ o estoque de capital da economia; e $L$ o estoque de trabalhadores; $\alpha$ e $\beta$ representam as elasticidades do capital e do trabalho em relação ao produto, respectivamente. A determinação de $A$ é

4. Uma descrição bem detalhada da estrutura e funcionamento do IFs pode ser acessada em: <http://www.ifs.du.edu/ assets/documents/StructureofIFsV1_0.pdf>.

5. Disponível em: <https://pardee.du.edu/>. Acesso em: 31 mar. 2020. 
obtida endogenamente por meio das produtividades do capital humano (medida pelos gastos em saúde e educaçáo), produtividade do capital social, produtividade do capital físico e produtividade do conhecimento (investimento em desenvolvimento e integração da economia local com o resto do mundo).

Com toda a estrutura do IFs integrada, o sistema busca responder a três das questóes básicas: i) Onde estamos? ii) Aonde parecemos ir? e iii) Onde queremos estar e como chegaremos lá? A primeira questão está associada aos padróes históricos mundiais, nacionais ou regionais, permitindo a compreensão de suas relaçôes e o acompanhamento de tendências. A segunda significa a compreensão de relações que vão além de uma tendência ou a extrapolação de uma série de dados. Aqui, o modelo subjacente ao sistema IFs busca representar as interaçôes entre os diversos agentes. A terceira questão relaciona-se à criação de cenários alternativos de forma a destacar os potenciais impactos de mudança nas açôes dos diferentes agentes. Assim, as hipóteses que o modelo sustenta se inserem nas questóes globais. ${ }^{6}$

Em resumo, o sistema IFs tem uma estrutura teórica que depende dos vários tipos de agentes, seus comportamentos e a forma como eles interagem. Ele está fundamentado em diversos modelos teóricos e é rodado tomando como base os dados contidos em séries históricas de 186 países. ${ }^{7} \mathrm{O}$ sistema de previsão está incorporado em uma interface interativa que possibilita aos usuários exibir os resultados do cenário base e dos cenários alternativos, além de permitir a visualização de séries históricas. Essa ferramenta assume papel importante no desenho de políticas públicas na medida em que cria possibilidades de se pensar o futuro por meio da criação de cenários. A mensuraçấo dos efeitos encadeados das decisóes dos agentes nos diversos níveis regionais, com o uso da ferramenta, permite estabelecer objetivos, classificar prioridades e explorar possibilidades com o uso de cenários alternativos.

\section{QUAL A TRAJETÓRIA ATUAL? SIMULAÇÕES E COMPARAÇÕES DO CENÁRIO BASE COM UM CENÁRIO ALTERNATIVO COM MELHORIAS DE PRODUTIVIDADE}

A partir de uma parceria entre algumas instituiçóes públicas brasileiras - como o Ipea, o Banco Nacional de Desenvolvimento Econômico e Social (BNDES) e a Companhia de Planejamento do Distrito Federal (Codeplan) - e o Programa das Naçóes Unidas para o Desenvolvimento (PNUD) e o Frederick S. Pardee Center for International Futures, da Universidade de Denver, foram realizadas simulaçôes para compreender as tendências da economia brasileira. Nessa parceria, um conjunto de hipóteses foi levantado e o modelo teve sua base de dados ampliada, com a desagregação das variáveis em níveis sub-regionais (UFs). Esse esforço criou condiçôes para a elaboração das projeçôes apresentadas neste artigo e, consequentemente, para as inferências obtidas a partir de tais projeçôes.

O exercício consiste na criação de um cenário atual da economia nacional projetado para 2030 e em uma simulação com um choque de melhoria de produtividade em nível nacional para o mesmo período. O modelo foi alimentado com dados até 2015 e o horizonte

6. Disponivel em: <https://www.du.edu/ifs/help/intro/purposes.html>. Acesso em: 9 ago. 2019.

7. Atualmente, a representação por países ou regiões é a menor desagregação geográfica que se pode atingir. Contudo, em alguns países (Brasil, Peru, Índia, Sri Lanka, Nepal etc.) existe um esforço para reduzir essa agregação para níveis ainda menores. No caso brasileiro, o PNUD, com o apoio de algumas instituições brasileiras (como Ipea, Codeplan, BNDES, entre outras), firmou convênio com o Pardee Center para a obtenção e a validação de dados em nível subnacional. A parceria entre PNUD e Pardee Center teve início em 2016, cujo objetivo foi a construção de cenários com base na Agenda do Desenvolvimento Sustentável de 2030. A proposta dos trabalhos entre essas instituições contempla o uso dos Objetivos de Desenvolvimento Sustentável (ODS) como pano de fundo para o desenvolvimento de cenários e relatórios estaduais. 
da simulação, neste exercício, atinge o ano de 2030. Será estudado aqui o comportamento de apenas duas variáveis: o crescimento do PIB per capita e a taxa de pobreza estimada no horizonte apresentado da simulação, ou seja, até 2030.

\subsection{0 mundo e o Brasil e o Nordeste}

Uma simulação a respeito do comportamento do PIB per capita das economias do planeta, agrupadas por regióes continentais (África, Ásia, Europa, América Latina, América do Norte e Oceania), nos permite traçar uma trajetória dessa variável até o horizonte temporal de 2030. Embora todas as regióes apresentem uma trajetória positiva de crescimento, chama a atenção o nível de desigualdades apresentadas entre elas. Além da diferença abissal entre a regiâo de menor PIB per capita (África) e aquela de maior PIB per capita (América do Norte), ${ }^{8}$ também chama a atenção nessa simulação o fato de as regiôes que apresentam as menores taxas de crescimento no período serem também aquelas de menor PIB per capita. Isso mostra que o mundo caminha para um futuro ainda mais desigual em termos de renda per capita.

O gráfico 1 apresenta o percentual da taxa média de crescimento das regiôes mundiais. Das seis regióes apresentadas no gráfico, América Latina e Caribe é a de menor crescimento médio ao longo da série projetada, com aproximadamente $0,7 \%$ ao ano (a.a.). Esse resultado é bastante desapontador, porque é nessa região (com exceção de um conjunto de países que se localizam na África) que se encontra a maior parte dos países de menor renda.

GRÁFICO 1

Taxa média de crescimento das regióes do mundo (2015-2030)

(Em \%)

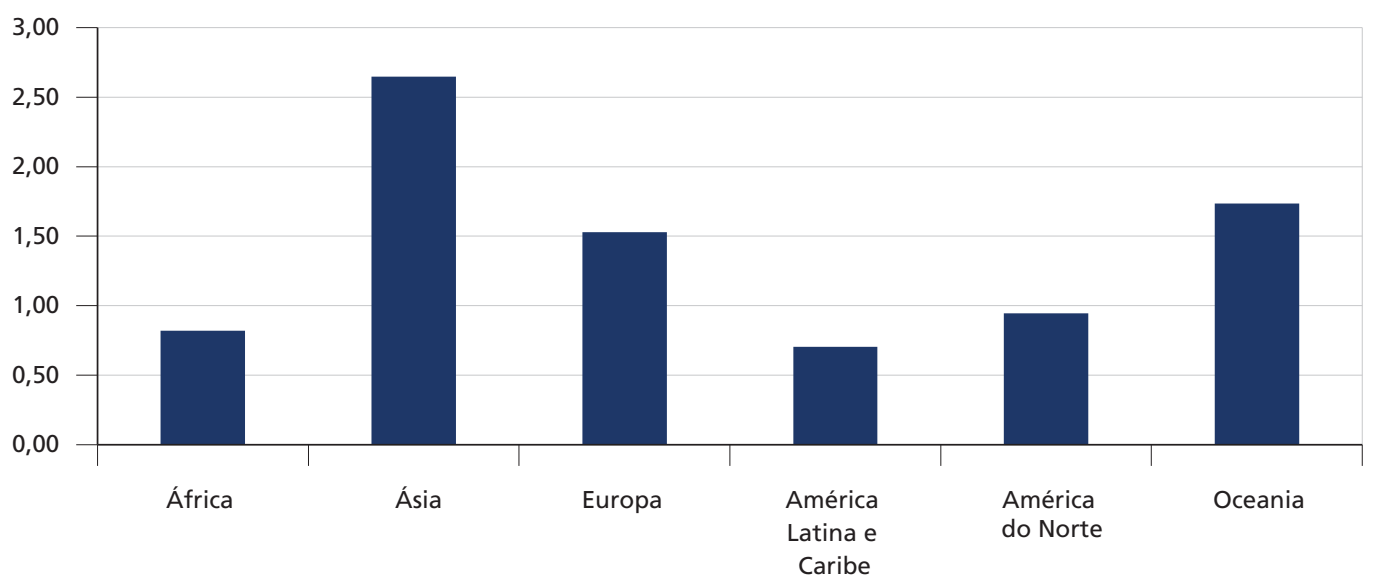

Fonte: IFs.

Elaboração dos autores.

Embora a região apresente um PIB per capita maior que o da Ásia no início da série, conforme mostra a tabela 1, em 2027 será superada pelos asiáticos e passará a ocupar a penúltima posição no ranking das regióes do planeta. Ainda assim, o comportamento do crescimento do PIB per capita da América Latina supera o crescimento observado para o Brasil (compare os resultados da tabela 1 com os apresentados na tabela 2 adiante).

8. Diferença essa que ultrapassa a $1.000 \%$. 
TABELA 1

Evolução do PIB per capita para regiões do mundo (2015-2030)

(Em US\$ mil a preços de 2011)

\begin{tabular}{|c|c|c|c|c|c|c|}
\hline Ano & África & Ásia & Europa & América Latina e Caribe & América do Norte & Oceania \\
\hline 2015 & 4,59 & 11,53 & 31,28 & 14,67 & 52,03 & 32,29 \\
\hline 2016 & 4,55 & 11,89 & 31,69 & 14,27 & 52,45 & 32,96 \\
\hline 2017 & 4,59 & 12,15 & 32,32 & 14,26 & 53,27 & 33,44 \\
\hline 2018 & 4,63 & 12,46 & 32,89 & 14,35 & 54,15 & 34,11 \\
\hline 2019 & 4,66 & 12,81 & 33,40 & 14,49 & 54,81 & 34,79 \\
\hline 2020 & 4,69 & 13,16 & 33,94 & 14,62 & 55,41 & 35,45 \\
\hline 2021 & 4,73 & 13,51 & 34,48 & 14,74 & 56,00 & 36,11 \\
\hline 2022 & 4,78 & 13,88 & 35,01 & 14,88 & 56,58 & 36,75 \\
\hline 2023 & 4,80 & 14,19 & 35,49 & 15,00 & 56,96 & 37,29 \\
\hline 2024 & 4,84 & 14,55 & 36,00 & 15,14 & 57,38 & 37,87 \\
\hline 2025 & 4,88 & 14,92 & 36,51 & 15,30 & 57,77 & 38,49 \\
\hline 2026 & 4,93 & 15,31 & 37,03 & 15,47 & 58,19 & 39,13 \\
\hline 2027 & 4,98 & 15,73 & 37,57 & 15,65 & 58,60 & 39,79 \\
\hline 2028 & 5,05 & 16,16 & 38,13 & 15,85 & 59,03 & 40,46 \\
\hline 2029 & 5,12 & 16,60 & 38,69 & 16,07 & 59,47 & 41,13 \\
\hline 2030 & 5,19 & 17,06 & 39,27 & 16,30 & 59,92 & 41,80 \\
\hline Crescimento médio (\%) & 0,82 & 2,65 & 1,53 & 0,70 & 0,95 & 1,74 \\
\hline
\end{tabular}

O Brasil, ao longo dos anos projetados, apresenta um crescimento médio em torno de $0,61 \%$ a.a. Na Ásia, tanto a China quanto a Índia crescem a uma taxa cinco vezes maior que a brasileira. Nessa trajetória, o PIB per capita chinês supera o brasileiro logo no início da série. Embora o crescimento do PIB per capita do Japão seja pouco mais que $40 \%$ do observado para a China e a Índia, em valores absolutos a riqueza média do Japão, medida para essa variável, supera a riqueza da Índia e mais de 6,5 vezes a da China e em quase três vezes a do Brasil.

O comportamento do PIB per capita para os estados do Nordeste e para o conjunto da economia brasileira, diante de uma situação normal, sem choques conjunturais de qualquer natureza que possam desviar a economia de sua trajetória de longo prazo, pode ser descrito na tabela 2. Esses dados mostram que o crescimento médio anual do PIB para o conjunto da economia do Nordeste, entre 2015 e 2030, é de aproximadamente 1,28\%, portanto, acima do crescimento médio anual da economia do país $(0,61 \%)$. Os estados cujas economias são menores apresentam crescimento ligeiramente superior a essa média, como é o caso de Alagoas, Maranhão, Paraíba e Piauí. Contudo, dois estados de economia pequena, Rio Grande do Norte e Sergipe, apresentam um comportamento diferente. Suas médias de crescimento ficaram abaixo da média do conjunto da região, com as menores taxas médias de crescimento.

Esse resultado parece ser contraintuitivo, visto que seria de se esperar que todas as economias da regiáo convergissem, dado que supostamente elas têm as mesmas características. No entanto, o resultado também mostra um possível aumento do grau de dependência dos estados menos desenvolvidos em relaçáo aos mais desenvolvidos. Esse é um pressuposto passível de investigação. Todavia, esse cenário não é muito animador, tendo em vista que o país e, sobretudo, a região Nordeste apresentam rendas per capita significativamente inferiores às dos países desenvolvidos. As políticas públicas voltadas para acelerar o crescimento da 
economia, tanto da região quanto do país, devem envolver ações relativas a aumento de produtividade e também políticas distributivas.

TABELA 2

Projeção do PIB per capita por estado do Nordeste e Brasil (2015-2030) (Em US\$)

\begin{tabular}{|c|c|c|c|c|c|c|c|c|c|c|}
\hline Ano/Estado & Alagoas & Bahia & Ceará & Maranhão & Paraíba & Pernambuco & Piauí & Rio Grande do Norte & Sergipe & Brasil \\
\hline 2015 & 7,01 & 8,14 & 7,41 & 5,74 & 7,14 & 8,48 & 6,19 & 8,40 & 8,68 & 14,81 \\
\hline 2016 & 6,74 & 7,83 & 7,13 & 5,55 & 6,89 & 8,15 & 6,01 & 8,03 & 8,32 & 14,11 \\
\hline 2017 & 6,83 & 7,92 & 7,22 & 5,63 & 6,99 & 8,27 & 6,16 & 8,02 & 8,31 & 14,20 \\
\hline 2018 & 6,94 & 8,05 & 7,34 & 5,71 & 7,10 & 8,40 & 6,23 & 8,10 & 8,39 & 14,37 \\
\hline 2019 & 7,06 & 8,20 & 7,46 & 5,85 & 7,26 & 8,56 & 6,50 & 8,20 & 8,49 & 14,52 \\
\hline 2020 & 7,18 & 8,35 & 7,59 & 5,99 & 7,41 & 8,71 & 6,70 & 8,30 & 8,58 & 14,65 \\
\hline 2021 & 7,27 & 8,44 & 7,68 & 6,10 & 7,51 & 8,80 & 6,86 & 8,37 & 8,66 & 14,74 \\
\hline 2022 & 7,35 & 8,55 & 7,76 & 6,20 & 7,63 & 8,91 & 7,02 & 8,46 & 8,75 & 14,83 \\
\hline 2023 & 7,44 & 8,65 & 7,85 & 6,31 & 7,75 & 9,01 & 7,17 & 8,53 & 8,81 & 14,93 \\
\hline 2024 & 7,53 & 8,75 & 7,95 & 6,42 & 7,87 & 9,12 & 7,33 & 8,61 & 8,88 & 15,04 \\
\hline 2025 & 7,64 & 8,87 & 8,07 & 6,54 & 8,01 & 9,25 & 7,50 & 8,70 & 8,96 & 15,17 \\
\hline 2026 & 7,77 & 9,01 & 8,21 & 6,68 & 8,17 & 9,39 & 7,69 & 8,81 & 9,06 & 15,34 \\
\hline 2027 & 7,91 & 9,17 & 8,35 & 6,84 & 8,33 & 9,54 & 7,90 & 8,92 & 9,16 & 15,53 \\
\hline 2028 & 8,06 & 9,33 & 8,52 & 7,00 & 8,51 & 9,70 & 8,13 & 9,05 & 9,27 & 15,74 \\
\hline 2029 & 8,23 & 9,51 & 8,69 & 7,17 & 8,72 & 9,87 & 8,40 & 9,19 & 9,39 & 15,97 \\
\hline 2030 & 8,41 & 9,69 & 8,86 & 7,34 & 8,94 & 10,05 & 8,69 & 9,34 & 9,53 & 16,22 \\
\hline Crescimento médio (\%) & 1,22 & 1,17 & 1,20 & 1,65 & 1,51 & 1,14 & 2,29 & 0,71 & 0,63 & 0,61 \\
\hline
\end{tabular}

\subsection{Comportamento do PIB per capita com choque de produtividade}

No que se refere a choques produtivos, propôs-se um exercício considerando a melhoria no desempenho de algumas variáveis que afetam diretamente a produtividade total dos fatores. Os pressupostos que orientam o choque de produtividade se assentam no acúmulo de capital físico, capital humano e avanço institucional. Certamente, as ações que guiam o acúmulo de capital envolvem políticas bem orientadas e explícitas. Conhecemos a importância de discutir de forma densa e consistente as melhores ações que os agentes (principalmente os públicos) poderiam tomar para otimizar o acúmulo de capital. Os choques, entretanto, para este exercício de simulação, são dados como exógenos.

Considera-se que a qualidade da educação é ponto-chave no acúmulo de capital humano. Portanto, somados a um conjunto de outras políticas, adotam-se, no modelo, os seguintes fatos para caracterizar ganhos na qualidade da educaçáo: sobre o ensino médio, considera-se que a média dos resultados dos testes de todas as disciplinas aumenta em $30 \%$; e para a educaçáo no ensino superior, a hipótese é que a proporção de formaturas em ciências e engenharias aumenta em $10 \%$, e a taxa de graduaçáo aumenta em $30 \%$. Ainda no que diz respeito a acúmulo de capital humano, considera-se a redução em 10\% nos casos de morte por razóes naturais, como neoplasia maligna, digestiva, cardiovascular, respiratória e saúde mental.

No que tange ao acúmulo de capital físico, as açôes focaram a infraestrutura, com aumento de $20 \%$ na densidade da malha rodoviária (estradas por extensão do território). Os avanços institucionais estão voltados para a eficácia do governo, cuja qualidade de seus 
serviços, supostamente, aumenta em $20 \%$ e vem acompanhada de uma elevação de $20 \%$ em seus gastos. Há também melhoria na percepção de corrupção do governo, com base na Transparência Internacional (TI) - mais alto é menos corrupto -, com aumento de $20 \%$. Por fim, supóe-se crescimento multifatorial da produtividade em $1 \%$ até 2030 - crescimento econômico anual de 1 ponto percentual (p.p.) até 2030.

$\mathrm{Na}$ tabela 3 sáo apresentados os dados dos PIBs dos estados do Nordeste para o período de 2015 a 2030, mas com choque de produtividade. Comparando os resultados dessa tabela com aqueles apresentados na tabela 2, percebe-se que os efeitos do aumento da produtividade tornam-se mais perceptíveis no decorrer do tempo. Ainda assim, o choque de produtividade não representou um crescimento significativo das economias da região. O crescimento médio anual das economias do Nordeste, com o choque de produtividade, foi de $1,92 \%$, apenas 0,64 p.p. acima do crescimento médio sem o choque de produtividade.

\section{TABELA 3}

Projeção do PIB per capita por estado do Nordeste e Brasil - com choque de produtividade (2015-2030) (Em US\$)

\begin{tabular}{lcccccccccc}
\hline Ano/Estado & Alagoas & Bahia & Ceará & Maranhão & Paraíba & Pernambuco & Piauí & Rio Grande do Norte & Sergipe & Brasil \\
\hline 2015 & 7,01 & 8,14 & 7,41 & 5,74 & 7,14 & 8,48 & 6,19 & 8,40 & 8,68 & 14,81 \\
2016 & 6,74 & 7,83 & 7,13 & 5,55 & 6,89 & 8,15 & 6,01 & 8,03 & 8,32 & 14,11 \\
2017 & 6,83 & 7,92 & 7,22 & 5,63 & 6,99 & 8,27 & 6,16 & 8,02 & 8,31 & 14,20 \\
2018 & 6,94 & 8,05 & 7,34 & 5,71 & 7,10 & 8,40 & 6,23 & 8,10 & 8,39 & 14,37 \\
2019 & 7,06 & 8,20 & 7,46 & 5,85 & 7,26 & 8,56 & 6,50 & 8,20 & 8,49 & 14,52 \\
2020 & 7,19 & 8,36 & 7,60 & 6,00 & 7,42 & 8,71 & 6,70 & 8,30 & 8,59 & 14,66 \\
2021 & 7,30 & 8,47 & 7,71 & 6,12 & 7,54 & 8,83 & 6,89 & 8,42 & 8,70 & 14,79 \\
2022 & 7,40 & 8,61 & 7,82 & 6,25 & 7,69 & 8,98 & 7,07 & 8,54 & 8,82 & 14,94 \\
2023 & 7,53 & 8,75 & 7,95 & 6,39 & 7,85 & 9,13 & 7,26 & 8,64 & 8,92 & 15,12 \\
2024 & 7,67 & 8,91 & 8,11 & 6,55 & 8,03 & 9,30 & 7,47 & 8,78 & 9,05 & 15,32 \\
2025 & 7,84 & 9,10 & 8,30 & 6,72 & 8,23 & 9,50 & 7,71 & 8,94 & 9,21 & 15,57 \\
2026 & 8,04 & 9,32 & 8,52 & 6,92 & 8,47 & 9,73 & 8,00 & 9,12 & 9,39 & 15,88 \\
2027 & 8,27 & 9,58 & 8,78 & 7,17 & 8,74 & 10,00 & 8,32 & 9,33 & 9,59 & 16,26 \\
2028 & 8,54 & 9,88 & 9,08 & 7,44 & 9,06 & 10,31 & 8,70 & 9,57 & 9,81 & 16,71 \\
2029 & 8,84 & 10,23 & 9,42 & 7,74 & 9,43 & 10,65 & 9,15 & 9,85 & 10,06 & 17,22 \\
2030 & 9,20 & 10,61 & 9,79 & 8,09 & 9,87 & 11,02 & 9,67 & 10,17 & 10,39 & 17,81 \\
Crescimento médio $(\%)$ & 1,83 & 1,78 & 1,88 & 2,31 & 2,18 & 1,76 & 3,02 & 1,28 & 1,21 & 1,24 \\
\hline
\end{tabular}

Fonte: IFs.

Elaboração dos autores.

Esse ganho a mais de crescimento na regiáo Nordeste é ligeiramente superior ao ganho observado no país, que foi de $1,24 \%$. Contudo, os efeitos da melhoria na produtividade dos fatores não impactariam táo significativamente a distribuição regional de renda.

\section{ALÉM DO PIB PER CAPITA: A DINÂMICA DA TAXA DE POBREZA EM TERMOS REGIONAIS}

Os maiores desafios de todas as sociedades ao longo da história estão assentados na geração de riqueza. A busca por métodos mais eficientes de produção tem aumentado a produtividade e o produto a ponto de rechaçar a tese malthusiana do século XVII, cujo principal (ou mais popular) desfecho era que o futuro da humanidade seria funesto, dado que náo haveria alimentos para todos. Ainda assim, a Organização das Naçóes Unidas (ONU) assinala para evidências que mostram que o nível global da pobreza não tem se alterado, enquanto o número 
total de desnutridos vem aumentando lentamente por vários anos seguidos. A instituição revela que uma em cada nove pessoas sofre de fome no mundo.

O número de pessoas em situaçáo de fome tem aumentado lentamente. Como resultado, mais de 820 milhôes de pessoas no mundo ainda estão em situação de fome, mostrando o imenso desafio de se atingir a meta de Fome Zero em 2030.

Se não há aqui um paradoxo, existe uma grande inconsistência: o excesso de produção coexiste com a incapacidade de acesso à produção por alguns. Daí, a questão da pobreza e da desnutrição se desassocia do problema da produçáo e recai em outro ponto delicado da ciência econômica: a distribuição. Fato é que o problema da distribuição (ou desigualdade) da riqueza é um fenômeno mundial e tem sido foco de atenção não somente da comunidade científica ou de formuladores de políticas públicas, mas também do conjunto da sociedade.

Se agrupássemos o mundo em regiōes continentais, como Ásia, Europa, Oceania, África e Américas, teríamos claramente regiôes ricas e pobres. Um olhar um pouco mais apurado nos revelaria que dentro dessas regióes ainda teríamos países ricos e países pobres, e, por sua vez, em nível subnacional existiriam regióes pobres e regiôes ricas.

No caso específico do Brasil, ao longo de sua história, o país passou por vários ciclos de crescimento econômico que foram acompanhados por momentos de desconcentraçáo regional de renda e momentos de concentração. Contudo, ainda que as políticas explícitas ou não de desenvolvimento regional buscassem arrefecer as desigualdades regionais de renda e bem-estar, o Brasil continua como um país bastante desigual. A regiáo Nordeste é claramente aquela que apresenta o menor nível de renda per capita do país.

O gráfico 2 mostra a evolução desse indicador nos anos recentes. Com exceção do Centro-Oeste, está clara a tendência de inércia em relação à mudança de posição das Grandes Regiōes nesse ranking.

\section{GRÁFICO 2}

PIB per capita por Grandes Regiões (1985-2011)

(Em R\$ de 2010)

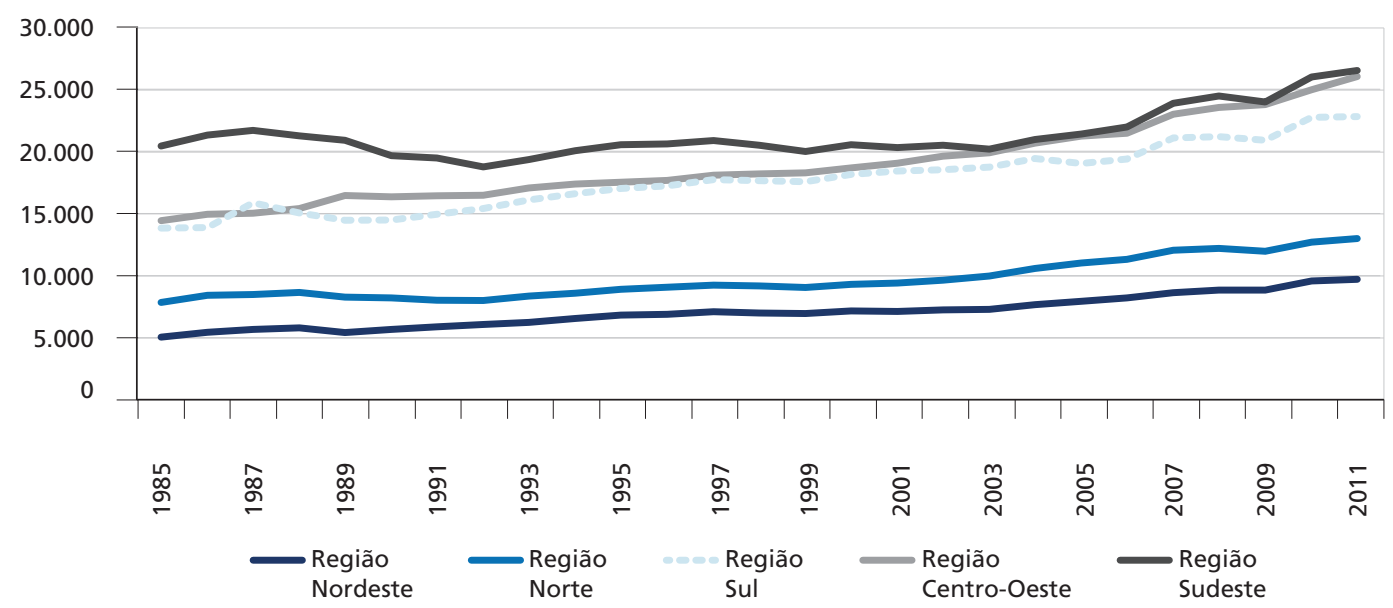

Fonte: IBGE.

A partir do conceito de linha de pobreza aceito internacionalmente, que estabelece o valor de US\$1.25 per capita como limite mínimo para que um indivíduo tenha condiçôes de obter

9. Disponível em: <http://www.fao.org/3/ca5162en/ca5162en.pdf>. Acesso em: 23 jan. 2020. 
recursos para sobreviver, foi projetado o comportamento da extrema pobreza para o Nordeste e o Brasil entre 2015 e 2030. A tabela 4 mostra essa projeção em porcentagem da população.

TABELA 4

Porcentagem de pessoas vivendo abaixo da linha de pobreza (2015 -2030)

\begin{tabular}{lrrrrrrrrrr}
\hline Ano & Alagoas & Bahia & Ceará & Maranhão & Paraíba & Pernambuco & Piauí & Rio Grande do Norte & Sergipe & Brasil \\
\hline 2015 & 7,2 & 5,5 & 6,7 & 10,7 & 5,8 & 6,2 & 6,1 & 5,1 & 4,1 & 3,1 \\
2016 & 7,6 & 5,8 & 7,2 & 11,2 & 6,1 & 6,6 & 6,3 & 5,5 & 4,5 & 2,7 \\
2017 & 7,4 & 5,6 & 7,0 & 11,0 & 5,9 & 6,4 & 6,2 & 5,4 & 4,5 & 2,6 \\
2018 & 7,2 & 5,4 & 6,8 & 10,8 & 5,8 & 6,1 & 6,1 & 5,3 & 4,4 & 2,5 \\
2019 & 7,0 & 5,2 & 6,6 & 10,5 & 5,6 & 5,9 & 5,7 & 5,2 & 4,3 & 2,4 \\
2020 & 6,8 & 5,0 & 6,4 & 10,2 & 5,4 & 5,6 & 5,5 & 5,0 & 4,2 & 2,2 \\
2021 & 6,6 & 4,9 & 6,3 & 10,0 & 5,3 & 5,5 & 5,3 & 4,9 & 4,1 & 2,2 \\
2022 & 6,5 & 4,7 & 6,1 & 9,8 & 5,1 & 5,3 & 5,2 & 4,8 & 4,0 & 2,1 \\
2023 & 6,3 & 4,5 & 6,0 & 9,5 & 5,0 & 5,1 & 5,0 & 4,7 & 4,0 & 2,0 \\
2024 & 6,1 & 4,4 & 5,8 & 9,3 & 4,9 & 4,9 & 4,8 & 4,6 & 3,9 & 2,0 \\
2025 & 5,9 & 4,2 & 5,6 & 9,1 & 4,7 & 4,7 & 4,7 & 4,4 & 3,9 & 1,9 \\
2026 & 5,7 & 4,0 & 5,5 & 8,9 & 4,5 & 4,5 & 4,5 & 4,3 & 3,8 & 1,8 \\
2027 & 5,5 & 3,8 & 5,2 & 8,6 & 4,4 & 4,3 & 4,3 & 4,1 & 3,7 & 1,7 \\
2028 & 5,3 & 3,6 & 5,0 & 8,3 & 4,2 & 4,1 & 4,0 & 4,0 & 3,6 & 1,7 \\
2029 & 5,1 & 3,4 & 4,8 & 8,0 & 4,0 & 3,9 & 3,8 & 3,8 & 3,5 & 1,6 \\
2030 & 4,8 & 3,2 & 4,6 & 7,8 & 3,8 & 3,7 & 3,5 & 3,6 & 3,4 & 1,5 \\
Variação & $-33,9$ & $-40,6$ & $-32,1$ & $-27,2$ & $-35,1$ & $-40,6$ & $-42,3$ & $-28,1$ & $-17,2$ & $-52,1$ \\
\hline
\end{tabular}

Fonte: IFs.

Elaboração dos autores.

Assim como no Brasil, em todos os estados do Nordeste há uma tendência clara de redução da população em condições de extrema pobreza. O país como um todo apresenta uma diminuição significativa no indicador (queda de aproximadamente 52\%). Estados como o Piauí apresentam uma reduçáo de mais de $42 \%$ no número de pobres entre 2015 e 2030. O que chama a atenção, porém, não é somente a tendência de queda dessas taxas, mas também o seu nível. Os dados para o Maranhão, por exemplo, mostram que, em 2015, quase $11 \%$ da população vivia em condiçôes de extrema pobreza. Apesar de uma significativa tendência de redução nesse indicador ao longo do período projetado, esse estado apresenta níveis significativos de extrema pobreza (cerca de $7,8 \%$ do total da população). O Brasil, de uma forma geral, apresenta taxas elevadas de extrema pobreza, e o Nordeste ainda consegue superar com valores significativos essas taxas.

A ONU, na sequência dos Objetivos de Desenvolvimento do Milênio (ODMs), pactuou com os países os ODS como forma de eles se comprometerem com dimensóes além do PIB per capita. Um dos indicadores é a chamada taxa de incidência de pobreza. O IFs possui uma miríade de variáveis como resultado, sendo possível analisar assim a tendência para cumprir as metas pactuadas. Seguindo, no entanto, o exercício apresentado neste artigo, a tabela 5 mostra o impacto sobre a redução da pobreza no Nordeste e no Brasil em consequência do choque de produtividade. 
TABELA 5

Porcentagem de pessoas vivendo abaixo da linha de pobreza - com choque de produtividade (2015-2030)

\begin{tabular}{|c|c|c|c|c|c|c|c|c|c|c|}
\hline Ano & Alagoas & Bahia & Ceará & Maranhão & Paraíba & Pernambuco & Piauí & Rio Grande do Norte & Sergipe & Brasil \\
\hline 2015 & 7,2 & 5,5 & 6,7 & 10,7 & 5,8 & 6,2 & 6,1 & 5,1 & 4,1 & 3,1 \\
\hline 2016 & 7,6 & 5,8 & 7,2 & 11,2 & 6,1 & 6,6 & 6,3 & 5,5 & 4,5 & 2,7 \\
\hline 2017 & 7,4 & 5,6 & 7,0 & 11,0 & 5,9 & 6,4 & 6,2 & 5,4 & 4,5 & 2,6 \\
\hline 2018 & 7,2 & 5,4 & 6,8 & 10,8 & 5,8 & 6,1 & 6,1 & 5,3 & 4,4 & 2,5 \\
\hline 2019 & 7,0 & 5,2 & 6,6 & 10,5 & 5,6 & 5,9 & 5,7 & 5,2 & 4,3 & 2,4 \\
\hline 2020 & 6,8 & 5,0 & 6,4 & 10,2 & 5,4 & 5,6 & 5,5 & 5,0 & 4,2 & 2,2 \\
\hline 2021 & 6,6 & 4,8 & 6,2 & 9,9 & 5,3 & 5,4 & 5,3 & 4,9 & 4,1 & 2,1 \\
\hline 2022 & 6,4 & 4,6 & 6,0 & 9,7 & 5,1 & 5,2 & 5,1 & 4,7 & 4,0 & 2,1 \\
\hline 2023 & 6,2 & 4,4 & 5,8 & 9,4 & 4,9 & 5,0 & 4,9 & 4,5 & 3,9 & 2,0 \\
\hline 2024 & 5,9 & 4,2 & 5,6 & 9,1 & 4,7 & 4,7 & 4,7 & 4,4 & 3,7 & 1,9 \\
\hline 2025 & 5,7 & 4,0 & 5,3 & 8,8 & 4,5 & 4,4 & 4,4 & 4,2 & 3,6 & 1,8 \\
\hline 2026 & 5,4 & 3,7 & 5,0 & 8,4 & 4,2 & 4,1 & 4,2 & 3,9 & 3,4 & 1,6 \\
\hline 2027 & 5,1 & 3,4 & 4,7 & 8,0 & 3,9 & 3,8 & 3,9 & 3,7 & 3,3 & 1,5 \\
\hline 2028 & 4,7 & 3,1 & 4,3 & 7,6 & 3,6 & 3,4 & 3,5 & 3,4 & 3,1 & 1,3 \\
\hline 2029 & 4,3 & 2,8 & 3,9 & 7,1 & 3,3 & 3,0 & 3,1 & 3,2 & 2,8 & 1,2 \\
\hline 2030 & 3,8 & 2,4 & 3,4 & 6,6 & 2,9 & 2,6 & 2,7 & 2,8 & 2,5 & 1,1 \\
\hline $\begin{array}{l}\text { Variação } \\
\text { percentual }\end{array}$ & $-46,9$ & $-56,0$ & $-49,0$ & $-38,5$ & $-49,9$ & $-57,5$ & $-55,9$ & $-44,2$ & $-37,4$ & $-65,5$ \\
\hline
\end{tabular}

Fonte: IFs.

Elaboração dos autores.

O gráfico 3 mostra a redução do percentual de pessoas (em valores absolutos) vivendo abaixo da linha de pobreza no período compreendido entre 2015 e 2030 para os dois casos: sem e com choque de produtividade. A maior queda na taxa de extrema pobreza ocorre no país como um todo, o que significa que, na média, as demais UFs conseguirão reduzir suas taxas de pobreza em uma velocidade maior que os estados do Nordeste. Contudo, o choque de produtividade no país faz com que a taxa de extrema pobreza caia em pouco mais de 13 p.p. O maior impacto se dá no estado de Sergipe, com uma redução superior a 20 p.p. Por sua vez, o Maranhão, cuja taxa de pobreza é a maior do país, apresenta o menor impacto, ou seja, é o estado com o menor crescimento em consequência do choque de produtividade.

Os choques de produtividade têm impactos relevantes sobre a redução da população que vive abaixo da linha de pobreza. Ainda assim, o país não conseguirá erradicar a extrema pobreza em 2030, como apregoava um dos dezessete ODS. A porcentagem de pessoas vivendo abaixo da linha de pobreza em 2030 ainda será extremamente elevada para alguns estados, como é o caso do Maranhão (6,6\%). 


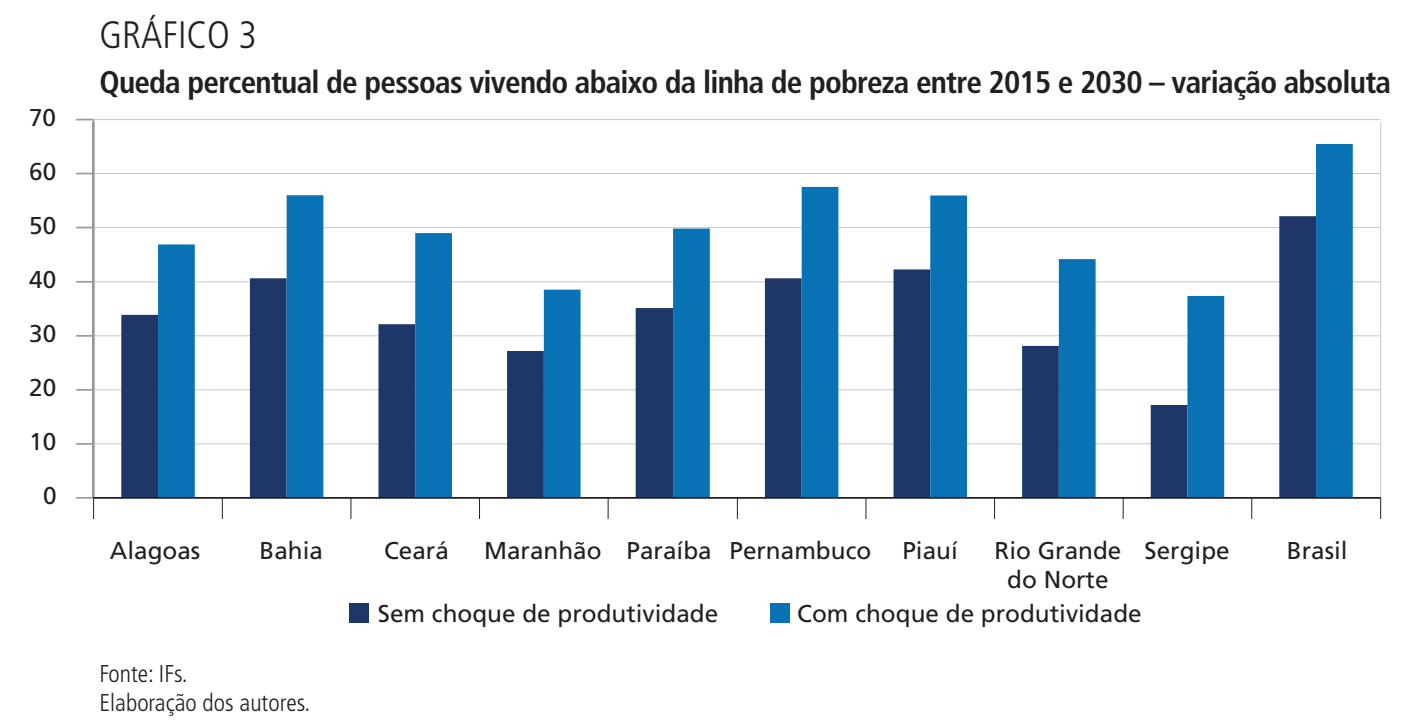

\section{COMENTÁRIOS FINAIS}

Este artigo abordou questôes relacionadas ao desempenho econômico dos estados da região Nordeste do Brasil, comparando um cenário padrão, sem movimentos importantes na economia, com políticas alternativas de crescimento de produtividade. Para isso, utilizou-se a ferramenta IFs, desenvolvida pela Universidade de Denver, que permite a construção de cenários para a economia mundial e com diversos blocos e interaçôes de um amplo conjunto de variáveis.

Alguns resultados importantes foram obtidos. O Brasil em ambos os cenários apresenta taxas de crescimento do PIB bem modestas. Mesmo com o choque de produtividade, a média de crescimento do país ficou na vizinhança de 1,33\%, ligeiramente acima do crescimento médio anual de sua economia, que é de $0,6 \%$ sem o referido choque. Os estados da regiáo Nordeste, embora apresentem uma taxa média de crescimento anual do PIB per capita acima da média do país, no fim do período, mesmo com choques de produtividades, não atingem $60 \%$ do PIB nacional. Em relação ao comportamento da pobreza no Nordeste, caracterizada pela parcela da população que vive abaixo da linha de pobreza, mesmo com o choque de produtividade, a região fica longe de extinguir a miséria.

Isso nos leva a considerar que políticas generalistas, que não sejam desenhadas observando-se as características da região, têm efeito limitado sobre a produção e a redução da pobreza. Os ganhos de produtividade se espalham pelo país, com efeitos positivos sobre o PIB do Nordeste, mas são insuficientes para tirar a regiâo da condição em que ela se encontra atualmente.

O uso da ferramenta do IFs nos permite traçar os efeitos de certas políticas sobre um conjunto de variáveis. Não devemos, contudo, nos esquecer de que essa é uma ferramenta construída para fazer projeçôes de longo prazo. Um conjunto de variáveis que não estão incorporadas no modelo pode afetar o curso da economia das regióes (por exemplo, o surgimento do coronavírus - Covid-19) e gerar resultados incompatíveis com aqueles apresentados pelo modelo. Isso não invalida, no entanto, o uso da ferramenta, uma vez que com ela pode-se atribuir real significado a um conjunto de políticas que se queira adotar. 